This PDF is a selection from a published volume from the National Bureau of Economic Research

Volume Title: Social Security Programs and Retirement around the World: The Relationship to Youth Employment

Volume Author/Editor: Jonathan Gruber and David A. Wise, editors

Volume Publisher: University of Chicago Press

Volume ISBN: 978-0-226-30948-4; 0-226-30948-7

Volume URL: http://www.nber.org/books/grub08-1

Conference Date:

Publication Date: February 2010

Chapter Title: Social Security, Retirement and Employment of the Young in Denmark

Chapter Author: Paul Bingley, Nabanita Datta Gupta, Peder J. Pedersen

Chapter URL: http://www.nber.org/chapters/c8253

Chapter pages in book: (99 - 117) 


\title{
Social Security, Retirement, and Employment of the Young in Denmark
}

\author{
Paul Bingley, Nabanita Datta Gupta, \\ and Peder J. Pedersen
}

\subsection{Introduction}

The demographic prospects in Denmark are, like those in most other rich Organization for Economic Cooperation and Development (OECD) countries, characterized by an increasing share of elderly people, that is, until the middle of the century. A decline in fertility, a trend until recently toward earlier retirement, and longer expected lifetimes interact to increase the share of elderly people in the population with derived impacts on the economy in many different ways; that is, on the public sector budget and on the relative as well as the absolute size of the labor force, unless policy changes are enacted.

A major part of the trend toward earlier retirement is, apart from the impact from higher incomes and wealth, explained by the introduction of programs for early retirement, either directly or by expanding other retirement programs with an early retirement option, intended to reduce youth unemployment and increase welfare for eligible older workers retiring through these programs. In this chapter we concentrate on the question of whether older workers retiring earlier from the labor force create job openings for young workers. If the number of jobs in the economy were of a given magnitude, there would exist a substitution of jobs between older and younger workers, which some might invoke as an argument in support of early retirement programs.

Paul Bingley is a professor at the Danish National Centre for Social Research. Nabanita Datta Gupta is a professor at the Aarhus School of Business and a guest researcher at the Danish National Centre for Social Research. Peder J. Pedersen is a professor at the School of Economics and Management of Aarhus University. 
The purpose of the present chapter is to study the eventual evidence for or against this substitution hypothesis over the thirty years up to the turn of the century, using microdata for employment, unemployment, and enrollment in education for different age groups in the Danish economy. In section 3.2 we describe briefly the demographic perspectives in Denmark along with the main elements of social security retirement programs. There are a number of important and potentially very informative policy reforms - performing as natural experiments - during this period that are exploited to provide variation identifying our estimated models. Next, section 3.3 contains a number of descriptive indicators of employment and unemployment for the young, the prime aged, and the older group organized around the policy changes that occurred between 1971 and 2001. Section 3.4 contains a number of regression results with the aim of getting a measure of the simple correlations between employment, unemployment, and labor force participation across age groups. This is followed by analyses in section 3.5 introducing incentive measures for the old as the structural factor creating the basis for an eventual substitution of old for young jobs. Section 3.6 concludes the chapter.

\subsection{Demographic Perspectives and Social Security Programs}

The official retirement age in Denmark defined as the time from which you become eligible for National Old Age Pension (OAP) is sixty-five years from 2004, reduced from sixty-seven years. ${ }^{1}$ The actual average retirement age is lower, at around sixty-one to sixty-two years. Due to this, the ratio shown in figure 3.1 underestimates the impact from the coming demographic shift by depicting the conventional calculation of the sixty-five years and older relative to the whole population and to the sixteen to sixty-four years old based on the most recent population forecast from Statistics Denmark.

With unchanged policies in the area of social security retirement programs, a forecast of more than a 20 percentage point increase in the dependency ratio shown in figure 3.1 will have quite strong implications for public expenditures with derived implication for taxes and/or public expenditures. Assuming unchanged labor force participation rates implies that the number of people in the labor force will go down and the consequence is a shrinking tax base at the same time as the increasing pressure on the expenditure side occurs. An obvious policy reaction is to consider changes in the rules regarding social security retirement with the double effect of reducing future

1. This is in contrast to the increase in eligibility ages enacted in most countries. The rational explanation of this change of rules is the fact that most people sixty-five and sixty-six years old were in an early retirement program - the PEW, compare following — with higher benefits than the OAP. 


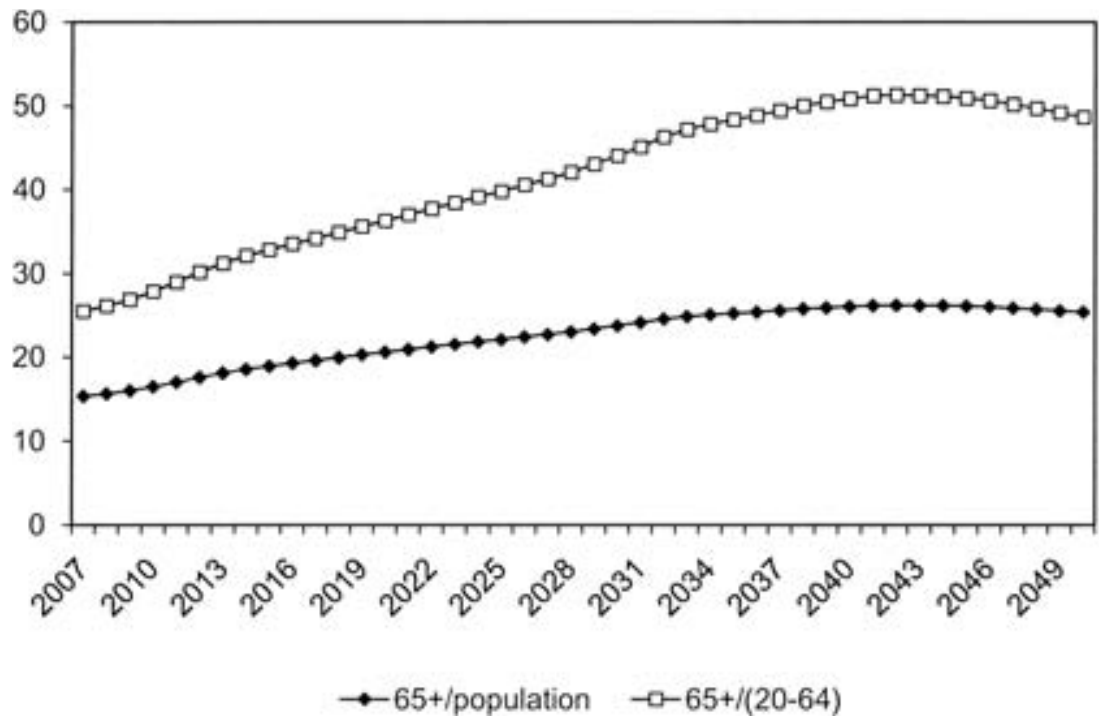

Fig. 3.1 The population sixty-five and older relative to the population and to the number of people sixteen to sixty-four years old

expenditures and increasing the future tax base. ${ }^{2}$ The projected composition on age groups of the twenty- to sixty-four-years-old is shown in figure 3.2. The share of young workers twenty to twenty-four years old is very stable for the whole forecast period up to 2050. It is seen that the main change in the first twenty years is a 5 percentage point decline in the share of the prime age group, twenty-five to fifty-four, followed by a nearly 5 percentage point decline in the share of workers fifty-five to sixty-four years old in the last twenty years of the forecast period.

As a background for the analyses in the subsequent sections, we present a brief survey of the Danish social security retirement programs. Regarding the eventual substitution of young for old jobs, a number of important program innovations have occurred in the last quarter of a century. Until 1979, National Old Age Pension (OAP) and social disability pension (SDP) were the only elements in the Social Security part of provision for retirement, along with unemployment or sickness benefits as a pathway to retirement. In 1977 a law-preparing committee was appointed to make an outline for an early retirement program where eligibility, in contrast to social disability pension, should depend on objective criteria and not on a visitation

2. Based on the work in a Government committee on Welfare, policy changes have been enacted to adjust the earliest ages of eligibility for both PEW and OAP programs to the average life expectancy. However, these changes become only effective as from 2019. 


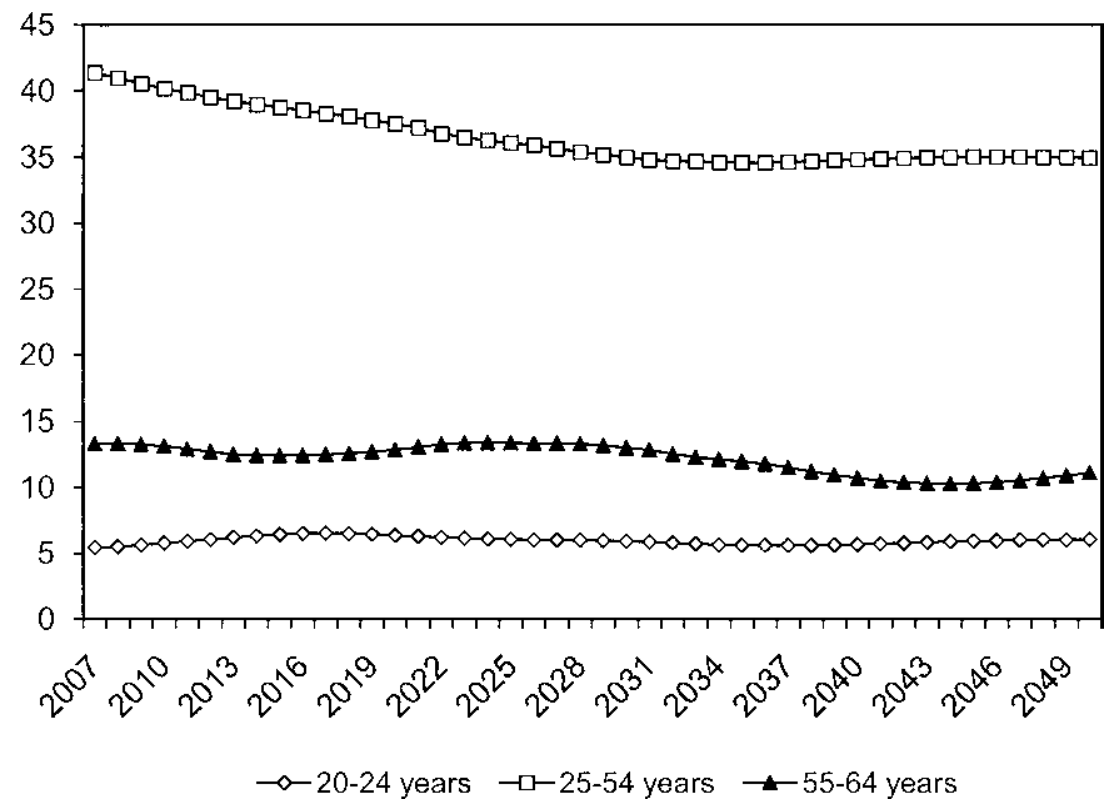

Fig. 3.2 Relative population shares twenty- to sixty-four-year-olds

on medical and/or social criteria. In the years before this committee was appointed, the union for unskilled workers had argued for the introduction of a program for early retirement where the target group was intended to be people with a long history of work in physically demanding jobs. The program was intended to be a more attractive option than disability pension. Based on this, the so-called Post Employment Wage (PEW) was introduced in 1979 as an early retirement program with eligibility based solely on being at least sixty years old and having sufficient tenure as member of an unemployment insurance fund. ${ }^{3}$

When the law introducing PEW was passed in parliament, one of the main arguments was that the program was supposed to be an element in labor market policy where a presumed fairly constant number of jobs should be redistributed from older workers (retiring early on the new program) to younger workers (among whom unemployment was high at the time). The secondary motive was to function as an alternative to disability pension for workers with a long record of physically demanding jobs. The main line of argument is expressed in a 1978 quote from the Minister of Labor, Svend Auken: "Unemployment among the youth is perhaps the most serious

3. Unemployment insurance is not mandatory in Denmark. Membership of so-called Ghenttype unemployment insurance funds is voluntary. The funds are administered by unions with revenues from membership fees and with the state as the actor carrying the residual financial burden under recessions. 
problem of today, because we cannot hide from the fact that we risk losing a whole generation of young persons from the labor market and from society as a whole ..." (Proceedings of Parliament, 1978). In the policy debate at the time of introduction of the program, counterarguments regarding the basic idea; that is, a more or less given number of jobs, was nearly absent. However, one member of parliament (chairman of a tax protest party at the time, called the Progress Party) named Mogens Glistrup in very colorful language expressed a deep skepticism regarding this argument: "This is a shimmering blue, lifelong-lying illusion used to trick the people into thinking that this legislation will reduce the ranks of the unemployed . . . with so much as even one single individual ... the laws of economics don't work that way ..." (Proceedings of Parliament, 1978).

The same basic motivation, a given number of jobs, was also used in the early 1980 s to motivate other, smaller policy changes. This was the case regarding some of the elements in a pension reform of 1984, containing the following.

- Stricter means testing of old age pension relative to earnings from work.

- Cancellation of a-modest - actuarial element in the old age pension program where the motive was to increase economic incentives for older workers to leave the labor force at the first eligible age.

Entry to the PEW program was very high compared to initial estimates in the policy preparation phase. Significantly more men than women in the affected age groups of sixty and above fulfilled the membership demands in the unemployment insurance funds. The very strong impact from the PEW program is illustrated in figure 3.3, which shows the labor force participation rate for men in the age group sixty to sixty-four years from before the introduction of PEW to the most recent period. The data for the long period covered by figure 3.3 are from different sources. Due to this, the decline in labor force participation at the time of introduction of PEW as shown in figure 3.3 may be biased somewhat upwards. The data for the years before PEW are either census data, 1960, 1965, and 1970, or survey-based (while they are based on the Register-based Labour Force Statistics [RAS] register since 1980 where all persons are classified relative to the labor market based on their main activity in the first week of November in the preceding year). An alternative illustration of the impact on the employment rate for men sixty to sixty-four years old is shown following, using consistent data for the period 1971 to 2001 based on mandatory contributions to a universal labor market pension program called ATP (Danish Labor Market Supplementary Pension Fund).

Although other factors, including SDP and occupational pensions with early retirement options also influence the participation rates, the timing of the changes depicted in figure 3.3 is narrowly related to characteristics of the 


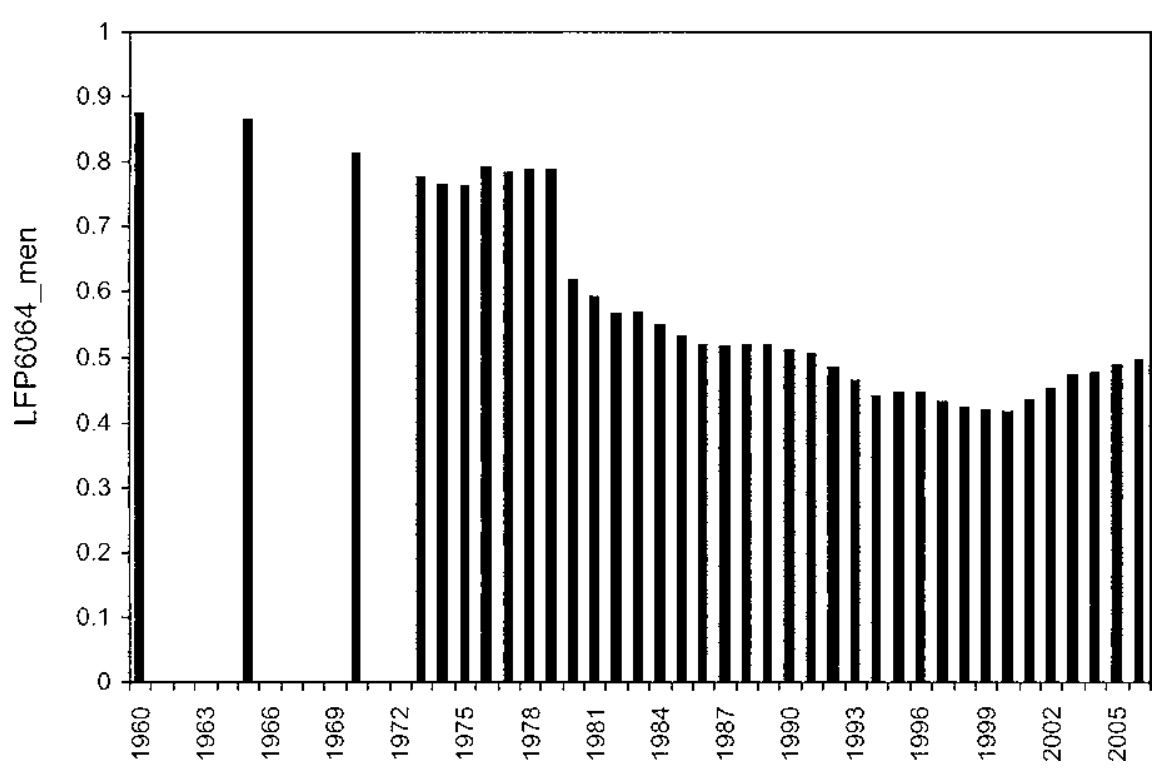

Fig. 3.3 Labor force participation rate for men, sixty to sixty-four years old, 1960 to 2006

PEW program. Immediately after the introduction of the program in 1979 the participation rate for the sixty- to sixty-four-year-old men goes down steeply from around 80 percent. Over the following twenty years participation declines further, with about 20 percentage points to close to half the pre-PEW level. In 1999 a policy reform was enacted with the purpose of reducing the economic incentives for entry into the program. In figure 3.3, we notice a fairly strong increase in participation rates in the most recent years, which most probably is due to the reform in 1999 and a shift of the statistical criteria for drawing the line between retirement and in the labor force, implying that a number of individuals receiving the PEW benefits at the same time had earnings from work high enough to shift them into the employed category of workers. More liberal rules for combining PEW with earnings from some work was part of the 1999 reform. In section 3.3 we treat the labor market reactions to PEW in more detail.

Besides the PEW program, a more restricted early retirement program in the Social Security area, called the Transitional Benefits Program (TBP), was opened for long term unemployed people fifty to fifty-four years old in 1992. In 1994 eligibility was extended to fifty-five to fifty-nine years old long term unemployed people. Entry was closed again in 1996. Benefits were set at 80 percent of PEW benefits and those admitted to the program remained in it and were transferred to the PEW program by the age of sixty. 


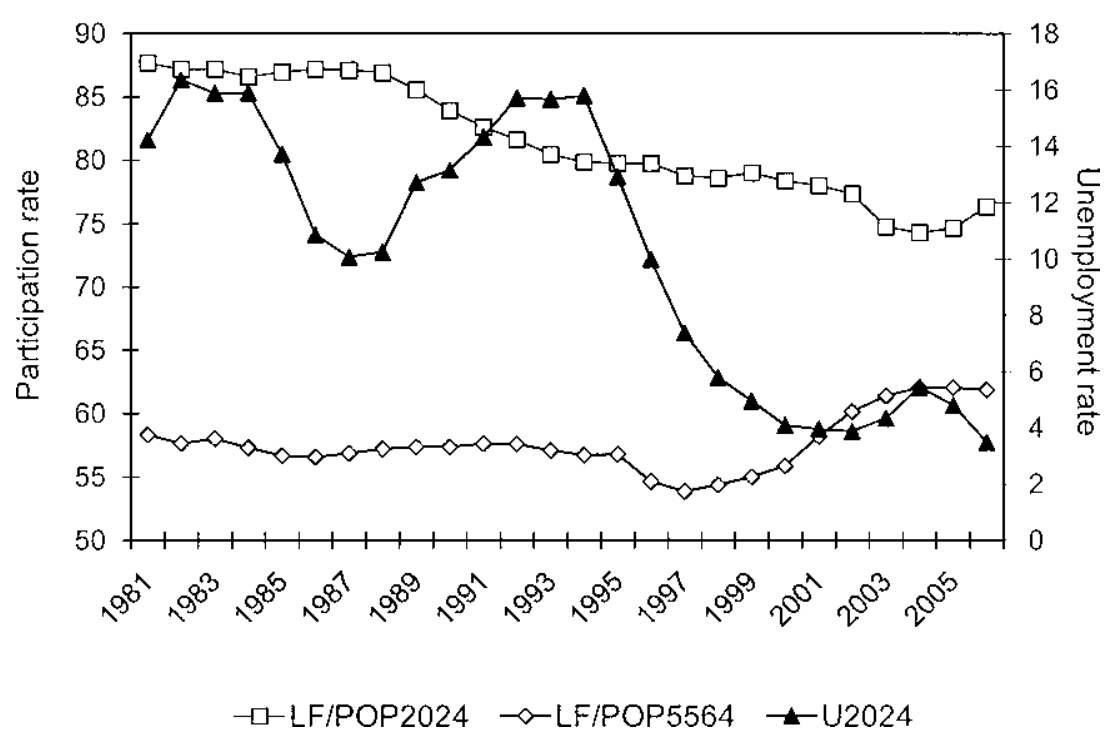

Fig. 3.4 Labor force participation twenty to twenty-four and fifty-five to sixty-four years old (unemployment twenty to twenty-four years old, 1981 to 2006)

\subsection{Description of Changes in Unemployment and Employment for Age Groups}

A first summary impression of the development in some relevant agerelated labor market indicators is given in figure 3.4 for women and men together. Figure 3.4 is based on the RAS data, which are consistent for the period 1981 to 2006 . The labor force participation rate for the old, defined as the fifty-five- to sixty-four-year-old group, shows a moderate decline from 1981 to the mid-1980s. The RAS data has 1981 as the first year, making it difficult to illustrate the impact from the PEW that was shown for sixty- to sixty-four-year-old men in figure 3.3. ${ }^{4}$ Based on alternative data we illustrate the change before and after the introduction of PEW. Further, the impact from the TBP on the labor force participation among people in their fifties is clearly visible in figure 3.4.

For the young, figure 3.4 contains two indicators. The labor force participation rate is nearly constant until the late 1980 s, followed by a decline of 10 percentage points until the turn of the century. Unemployment shows big cyclical movements until the mid-1990s around a high level, followed by a steep decline to a very low level at the end of the period. Based on figure

4. By convention, the RAS data for a given year $t$ indicates the state relative to the labor market for all individuals in November of year $t-1$. 


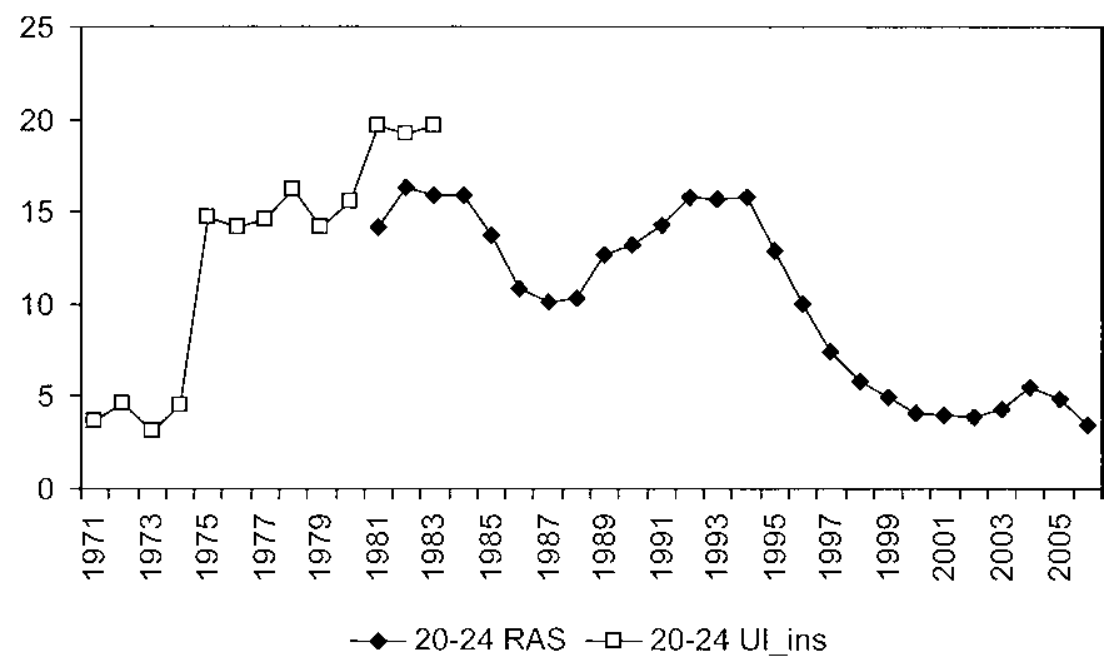

Fig. 3.5 Unemployment, twenty to twenty-four years old (1971 to 1983, no. of fulltime insured unemployed/no. of insured, 1981 to 2006, based on the RAS register)

3.4, there is no indication of any impact from PEW on youth unemployment. A fundamental policy change regarding unemployed younger than twenty-five enacted in 1994 seems, on the other hand, to have had a strong effect on youth unemployment-supported by a general cyclical upturn beginning in 1994.

It is obviously interesting, considering the natural experiment nature of the introduction of PEW to go back beyond 1981. The problem with this approach is that we have to link different series. This is illustrated in figures 3.5 and 3.6, including the whole period from 1971. The RAS data as mentioned starts off in 1981. Before that, insurance-based data are available reporting unemployment by age for full time insured workers twice a year, respectively, for January and July. The average values are shown in figure 3.5, which includes, for illustration, three overlapping years.

Finally, figure 3.6 shows the profile for youth unemployment 1971 to 2006 with the two series linked in 1981. The very strong increase, beginning at the time of the first oil price shock, was part of the motivation for PEW (compare to the previous discussion). On the other hand, just comparing trends in aggregate series, no impact is seen from PEW on youth unemployment.

In figure 3.7, covering the period 1981 to 2006, labor force participation for the young in figure 3.4 has been replaced with unemployment in the prime age group. It can be seen that unemployment for the two age groups correlate in the first part of the period and practically become equal to each other since the late 1990s.

Finally, figure 3.8 collects labor force participation rates for the young, the 


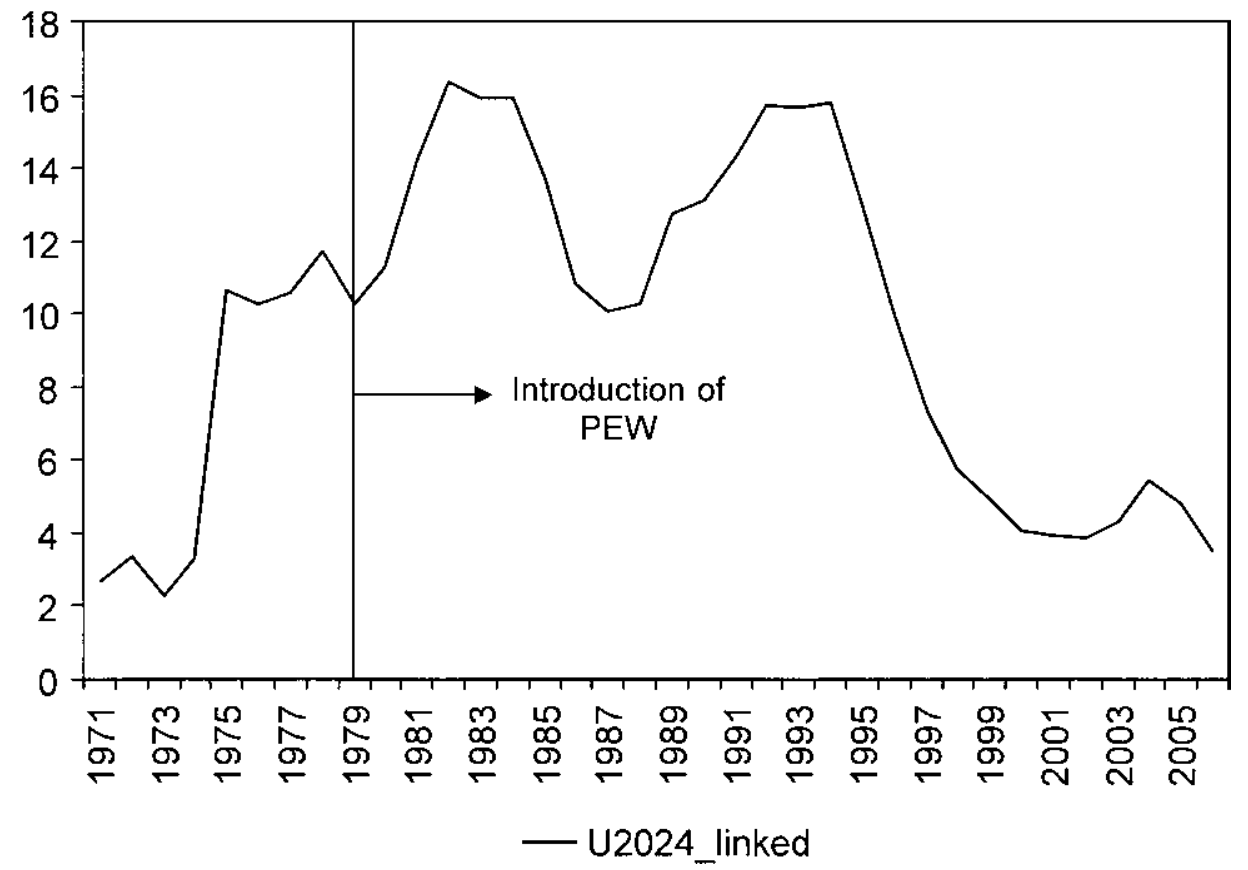

Fig. 3.6 Linked unemployment rate, twenty to twenty-four years old, 1971 to 2006

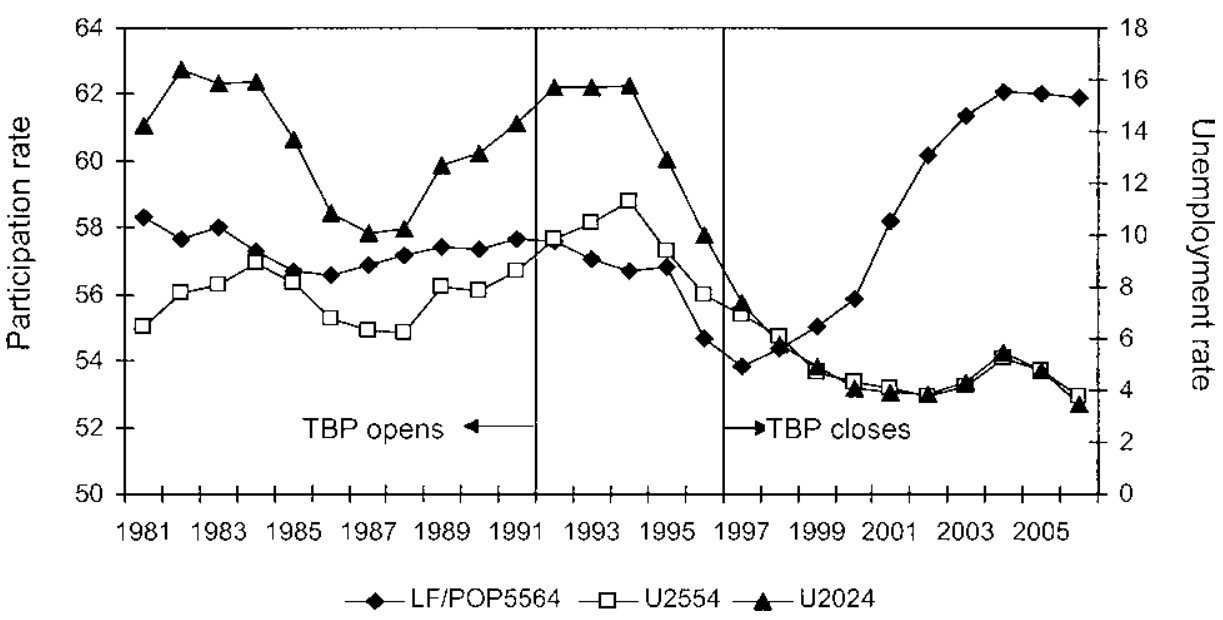

Fig. 3.7 Labor force participation fifty-five to sixty-four years old and unemployment rates for the young, twenty to twenty-four years, and the prime age group, twenty-five to fifty-four years old 


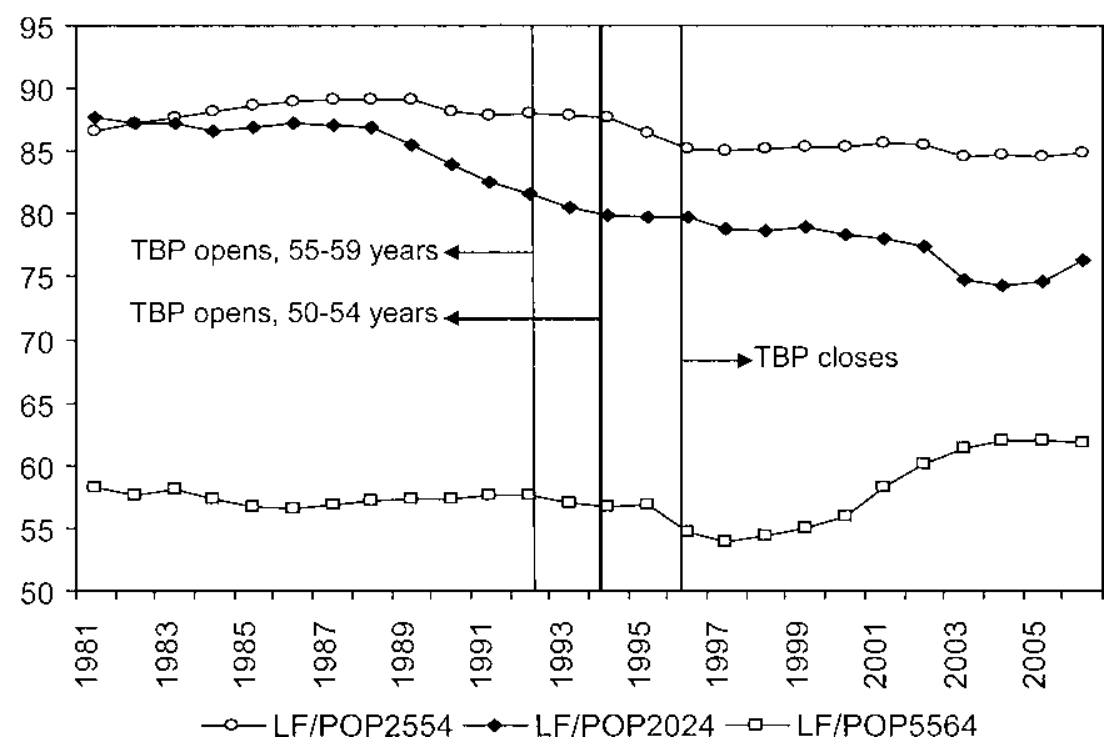

Fig. 3.8 Labor force participation rates, twenty to twenty-four, twenty-five to fiftyfour and fifty-five to sixty-four years old, 1981 to 2006

prime age group, and older workers fifty-five- to sixty-four-years-old in one graph. The most spectacular change is the decline in labor force participation among the young beginning in the late 1980s. The big changes for the group of older workers are not captured in figure 3.8 due to the series in the graph beginning after the PEW introduction and due to the aggregation of two groups below and above sixty years of age.

In figure 3.9 to 3.11 we extend the time scale to begin in 1971; that is, before the first oil price shocks and before the enactment of PEW. Figure 3.9 shows the employment share for men and women combined and disaggregating to two age groups in their fifties and the PEW relevant sixty- to sixty-four-year-old group. The employment data are from the microdata set and are complete for the age groups included here. Looking first at the oldest group, the falling employment rate until introduction of PEW is affected by the cyclical downturn after the oil price shock, where older workers who became unemployed subsequently had great difficulties entering a new job. The impact from PEW is clearly visible until the leveling-off in the employment rate as the economy moves up strongly in the mid-1990s.

Figures 3.10 and 3.11 show the profiles over time for men and women separately. It has been mentioned before that a higher proportion of men fulfilled the conditions for entering PEW. As a consequence of that, the impact from PEW is much more pronounced and concentrated in time for men. For women the cohort effect implies that employment rates for women 


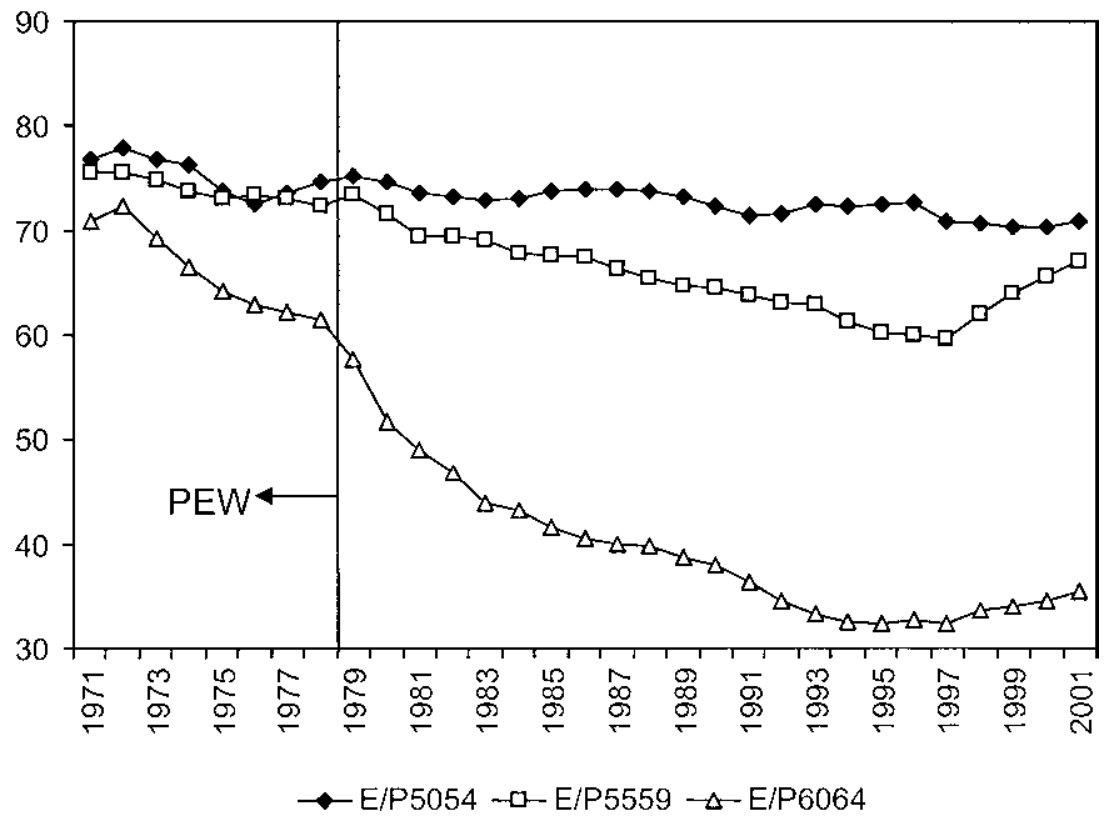

Fig. 3.9 Employment rates, fifty to sixty-four years old, 1971 to 2001 (based on microdata)

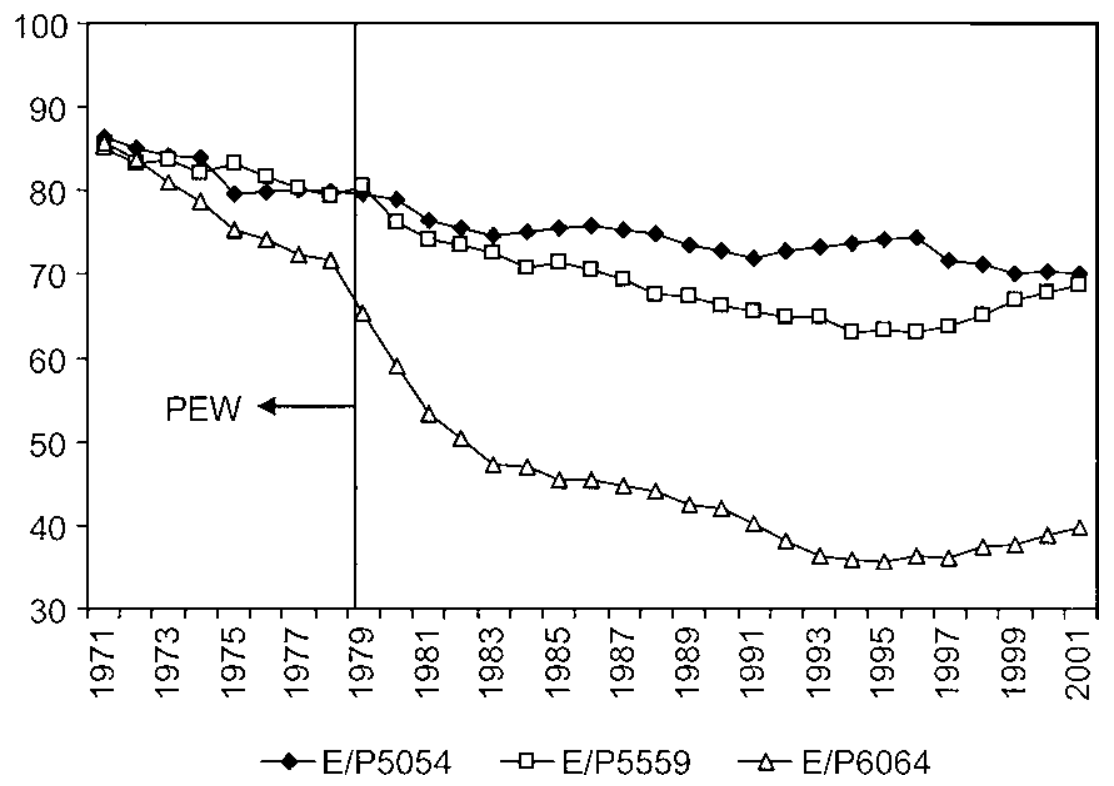

Fig. 3.10 Employment rates, fifty to sixty-four years old, men, 1971 to 2001 (based on microdata) 


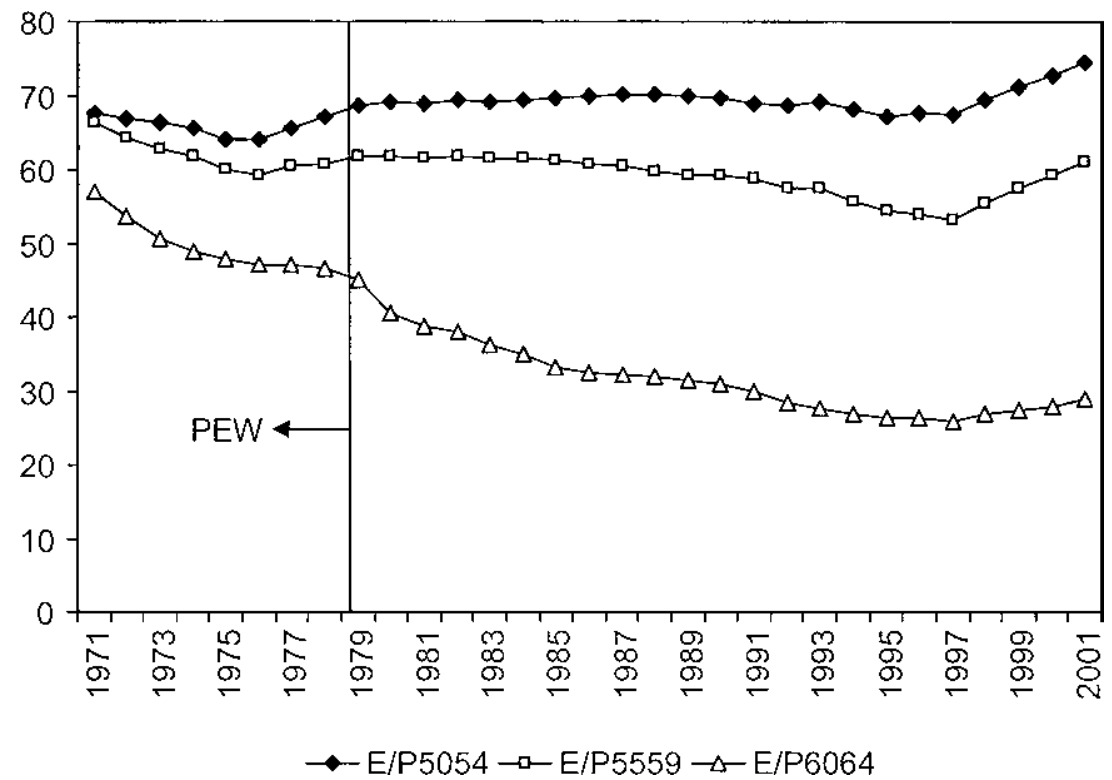

Fig. 3.11 Employment rates, fifty to sixty-four years old, women, 1971 to 2001 (based on microdata)

in their fifties are stable or slightly increasing up to the same level to which the rates for men are decreasing.

The data covering the longer period are based on microdata where employment is derived from payment of contributions to a mandatory pension called ATP. To evaluate the validity of the ATP-based data relative to the RAS data, we have looked into the difference between male employment in different age groups using the two data sources for an overlapping period. The overall impression is that the two employment series are highly correlated and can substitute for each other in regressions with a level difference only.

Finally, figure 3.12 extends figure 3.7 by including the years 1971 to 1980 . In the recession years 1974 to 1983 , the employment rate for older workers declines at the same time as unemployment goes up, most pronounced for the young, but also for the prime age group. From the mid-1980s to the mid-1990s unemployment moves cyclically around a high level for both age groups, while employment for the older workers continues the downward trend. Finally, from the mid-1990s a cyclical upturn begins with unemployment rates going down steeply while employment stabilizes among the older workers. Comparing these trends does not lend support to a substitution going on between jobs for the old and the young or the prime age group. In the next two sections we go on to examine this question in a regression setting. 


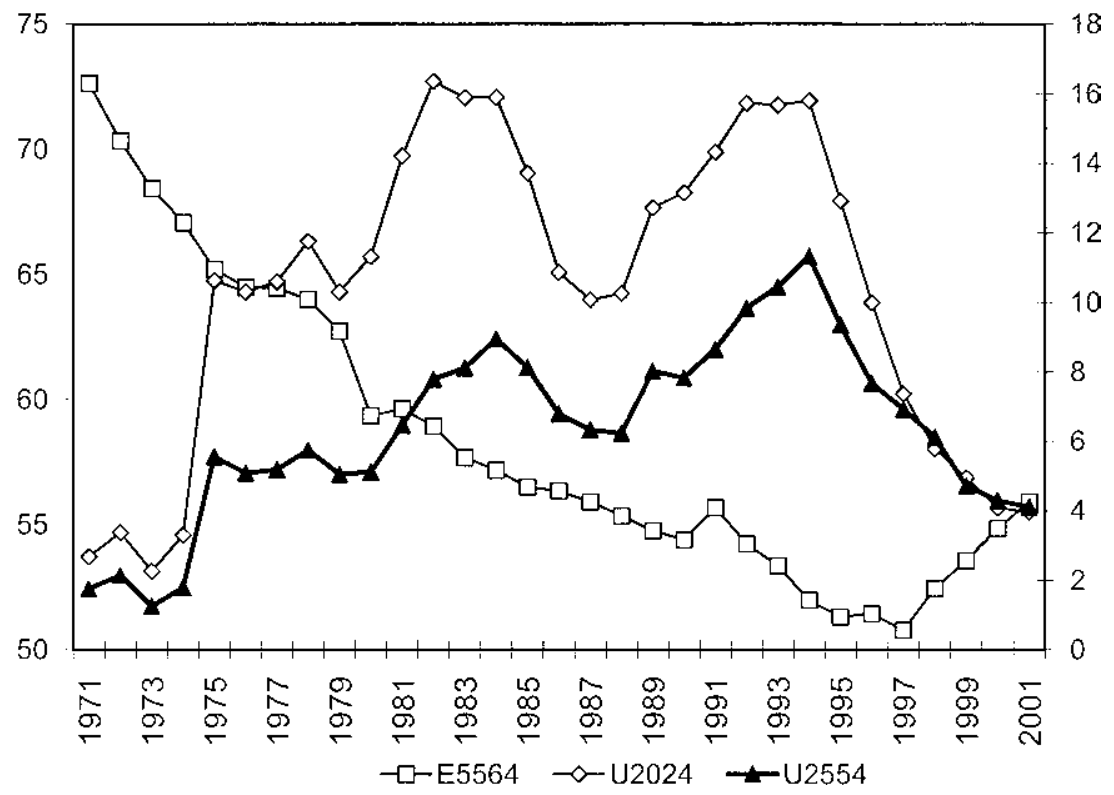

Fig. 3.12 The employment rate, fifty-five to sixty-four years old, and the unemployment rates for young, twenty to twenty-four, and prime age group, twenty-five to fifty-four, 1971 to 2001

\subsection{Elderly Employment and Youth and Prime Age Activity}

In this section we move from graphical evidence in the previous section to presenting descriptive ordinary least squares (OLS) time series regressions of youth and prime age activity explained by elderly employment. This allows a more careful description by controlling for a number of factors by covariates or transformations of the data. Coefficients on elderly employments from these various transformations with and without controls are presented in table 3.1 .

The upper panel reports coefficients from regressions without additional covariates. The lower panel controls for gross national product (GNP), GNP growth, and manufacturing employment share. Dependent variables are rates throughout, and within each panel the four lines represent different transformations of the data. First, we regress on untransformed levels (of rates) on levels; second, we regress levels on three-year lags to allow for a time lag in the response; third, we regress five-year differences on five-year differences; and fourth, we regress log of five-year differences on log of five-year differences where the transformations rid the data of nonstationarities.

The first three columns show youth behavior and the last two columns 
Table 3.1 Direct relationship between elderly employment and youth and prime age activity

\begin{tabular}{|c|c|c|c|c|c|}
\hline Specification & $\begin{array}{c}\text { Sample } \\
\text { Youth } \\
\text { UE }\end{array}$ & $\begin{array}{l}\text { Youth } \\
\text { EMP }\end{array}$ & $\begin{array}{l}\text { Youth } \\
\text { SCH }\end{array}$ & $\begin{array}{l}\text { Prime } \\
\text { UE }\end{array}$ & $\begin{array}{l}\text { Prime } \\
\text { EMP }\end{array}$ \\
\hline \multicolumn{6}{|l|}{ No controls } \\
\hline Levels & $\begin{array}{r}-0.407 \\
0.210\end{array}$ & $\begin{array}{r}-0.044 \\
0.055\end{array}$ & $\begin{array}{r}-4.180 \\
0.187\end{array}$ & $\begin{array}{r}-0.164 \\
0.031\end{array}$ & $\begin{array}{r}-0.175 \\
0.020\end{array}$ \\
\hline 3-year lag & $\begin{array}{l}0.109 \\
0.213\end{array}$ & $\begin{array}{l}0.023 \\
0.058\end{array}$ & $\begin{array}{r}-3.412 \\
0.219\end{array}$ & $\begin{array}{r}-0.086 \\
0.034\end{array}$ & $\begin{array}{r}-0.143 \\
0.022\end{array}$ \\
\hline $\begin{array}{l}\text { 5-year } \\
\quad \text { difference }\end{array}$ & $\begin{array}{r}-2.600 \\
0.509\end{array}$ & $\begin{array}{r}-0.049 \\
0.243\end{array}$ & $\begin{array}{r}-2.466 \\
0.638\end{array}$ & $\begin{array}{r}-0.376 \\
0.117\end{array}$ & $\begin{array}{r}-0.159 \\
0.081\end{array}$ \\
\hline $\begin{array}{l}\text { 5-year log } \\
\text { difference }\end{array}$ & $\begin{array}{r}-4.981 \\
1.516\end{array}$ & $\begin{array}{l}0.034 \\
0.151\end{array}$ & $\begin{array}{r}-0.659 \\
0.169\end{array}$ & $\begin{array}{r}-3.147 \\
1.187\end{array}$ & $\begin{array}{r}-0.086 \\
0.056\end{array}$ \\
\hline \multicolumn{6}{|l|}{ With controls } \\
\hline Levels & $\begin{array}{r}-2.691 \\
0.255\end{array}$ & $\begin{array}{r}-0.088 \\
0.153\end{array}$ & $\begin{array}{r}-2.764 \\
0.348\end{array}$ & $\begin{array}{r}-0.391 \\
0.070\end{array}$ & $\begin{array}{r}-0.212 \\
0.055\end{array}$ \\
\hline 3-year lag & $\begin{array}{r}-1.845 \\
0.396\end{array}$ & $\begin{array}{l}0.004 \\
0.163\end{array}$ & $\begin{array}{r}-1.747 \\
0.478\end{array}$ & $\begin{array}{c}-0.0261 \\
0.085\end{array}$ & $\begin{array}{r}-0.223 \\
0.058\end{array}$ \\
\hline $\begin{array}{l}\text { 5-year } \\
\quad \text { difference }\end{array}$ & $\begin{array}{r}-3.254 \\
0.652\end{array}$ & $\begin{array}{r}-0.390 \\
0.362\end{array}$ & $\begin{array}{r}-3.182 \\
0.937\end{array}$ & $\begin{array}{r}-0.433 \\
0.177\end{array}$ & $\begin{array}{r}-0.279 \\
0.124\end{array}$ \\
\hline $\begin{array}{l}\text { 5-year log } \\
\text { difference }\end{array}$ & $\begin{array}{r}-3.774 \\
4.039\end{array}$ & $\begin{array}{l}0.020 \\
0.363\end{array}$ & $\begin{array}{r}-0.241 \\
0.447\end{array}$ & $\begin{array}{r}-1.374 \\
3.145\end{array}$ & $\begin{array}{r}-0.158 \\
0.112\end{array}$ \\
\hline
\end{tabular}

prime age work. Focusing on the results for the youth (with no controls added), an increase in elderly employment in the differenced specifications has a statistically significant and negative impact on youth unemployment but no effect in the levels or three-year lag specification. This finding does not carry over to effects on youth employment, however, which are insignificant no matter which transformation of the data is being considered. On the other hand, in both levels and differences, youth enrollment is significantly reduced when elderly employment increases. Thus, the evidence suggests either complementarity or no relationship at all between elderly and young labor. For prime aged workers, we find again that unemployment is significantly reduced when elderly employment increases but that no clear statistical relationship between elderly employment and prime age employment can be discerned.

Adding controls for GNP, GNP growth, and manufacturing share reinforces the patterns found previously in the case of the first three transformations: that is, youth unemployment is significantly reduced, no significant effect is found for youth employment, and youth enrollment decreases significantly. For prime aged workers, adding controls results in both unemployment and employment being significantly reduced when elderly employment increases, which on the face of it appears somewhat puzzling. In the case of the last transformation - the five-year log difference-effects on 
both youth and the prime aged become imprecise and all statistical significance vanishes.

To summarize, the results from table 3.1 in which we seek to establish a direct relationship between elderly employment and youth (and prime age) activity turn up no evidence that an increase in elderly employment crowds out youth employment. Rather, in the instances where we can discern a clear relationship, youth unemployment and youth enrollment tend to decrease as elderly employment increases, suggesting complementarity between these worker groups.

\subsection{Retirement Incentives and Employment}

One concern with the correlations presented in the previous section is that the time series might have common but unobserved determinants. To make a more credible claim about measuring the effect of elderly employment on youth and prime age workers we use variation in social security provision for the elderly. Our previous work has shown that, based on individual microdata, more generous social security provision for the elderly induces earlier retirement. The challenge now is to aggregate up from an individual-based incentive to a summary index of the annual incentives to retire for the elderly together. A higher value of this index should reduce total elderly employment, consistent with micro evidence. Assuming that retirement incentives affect younger workers only through their effect on elderly employment, the correlation between the summary index and youth and prime age activity indicates a direct effect of elderly employment on younger workers.

A summary index of retirement incentives needs to incorporate social security eligibility conditions and levels and trajectories of potential entitlements for retiring now and later. Concepts of social security wealth (SSW) and peak value (PV) developed in Gruber and Wise (1999) and used in our previous work have been found to capture incentives well at the individual level. The SSW is the discounted present value of social security benefits received from the present until death, if retiring this year. It is assumed that individuals discount the future at 3 percent per year, use age-gender life tables (1980 life table is used 1980 to 1989,1990 life table for 1990 to 1999, and so forth, but assuming no chance of survival beyond age 100) and believe that current social security rules will remain in force indefinitely. At the current age an individual can calculate SSW for retiring this year and for staying in work until retirement at any future age (assumed latest age eighty). For future retirement, intervening net earnings predictions are assumed calculated from age-specific means in the current year. Comparing SSW for retiring in this and all future years we can obtain PV, which is the maximum.

In order to capture variation in incentives across the population and over time we create a simulated data set of combinations of: ten levels of earnings 
(the midpoints of deciles of the earnings distribution) $\times 2$ genders $\times 2$ marital states $\times 3$ pension program eligibilities (post employment wage, or public employees pension, or neither) $\times 2$ disability states (eligible for social and disability pension or not) $\times 31$ years (1971 to 2001). Our aim is to collapse incentive measures from these 7,440 simulated individuals into thirty-one annual summary indexes to be used in time series regressions. The index should reflect the retirement incentives faced by currently retired individuals when they were still in the labor force.

In order to explain construction of the index, consider a simplified example for the sake of illustration where we want to construct the index for 1990. Assume first age of social security eligibility is sixty. Those currently retired and aged sixty in 1990 must have retired in 1990 and the relevant incentive measure is obviously the mean incentive measure (a function of SSW and PV) for sixty-year-olds in 1990. Those currently retired and aged sixty-one in 1990 could have retired aged sixty in 1989 or aged sixty-one in 1990. A mean incentive measure for these currently retired sixty-one-yearolds needs to weight them according to their chance of being exposed to these incentives at these ages: employment rate of fifty-nine-year-olds in 1988 and sixty-year-olds in 1989, respectively. This can be extended until, say, those currently retired and aged sixty-six in 1990 - who could have retired at sixty in 1984, sixty-one in 1985, sixty-six in 1990 - and combined with relative exposure weights: employment rates of fifty-nine-year-olds in 1983, sixty in 1984, sixty-five in 1989, respectively. Hence, for the stock of current retirees aged sixty to sixty-six in 1990 we have seven incentive measures. Together these are weighted by the proportion of retirees of each age to form a single measure.

Consider the following function of SSW and PV, which should be aggregated

$$
I(a, y, \alpha)=\operatorname{SSW}(a, y)+\alpha[\operatorname{SSW}(a, y)-\operatorname{PV}(a, y)],
$$

where an individual at age $a$ in year $y$ is giving the gains delaying retirement (within square brackets) weight $\alpha$. This weighting allows discounting of future gains beyond the 3 percent already accounted for in SSW and PV calculation: $\alpha=0$ implies myopia and disregarding future gains, $\alpha=1$ implies no departure from standard discounting. Variable $\alpha$ is determined by comparing goodness-of-fit from OLS regressions explaining elderly employment by GNP, GNP growth, manufacturing employment share, and $I(\alpha)$ calculated using different values for $\alpha$. We tried $\alpha$ in the range 0 through 1.50 in steps of 0.25 and found 1.25 yielded the highest $R$-squared.

Simulated individuals are first assumed to be at risk of retirement at age fifty and must retire at (the latest) age eighty. In order to calculate weights it is necessary to back-cast earnings trajectories and employment probabilities. We observe the distribution of earnings in microdata back to 1977 and simulate earnings trajectories for decile midpoints before that date by 
Retirement incentives and elderly, youth and prime age activity

\begin{tabular}{lrrrrrrr}
\hline Specification & $\begin{array}{c}\text { Sample } \\
\text { elderly } \\
\text { UE }\end{array}$ & $\begin{array}{c}\text { Elderly } \\
\text { EMP }\end{array}$ & $\begin{array}{c}\text { Youth } \\
\text { UE }\end{array}$ & $\begin{array}{r}\text { Youth } \\
\text { EMP }\end{array}$ & $\begin{array}{c}\text { Youth } \\
\text { SCH }\end{array}$ & $\begin{array}{r}\text { Prime } \\
\text { UE }\end{array}$ & $\begin{array}{r}\text { Prime } \\
\text { EMP }\end{array}$ \\
\hline No controls & & & & & & & \\
Levels & 0.037 & -0.189 & 0.058 & 0.003 & 0.788 & 0.029 & 0.033 \\
& 0.007 & 0.009 & 0.042 & 0.011 & 0.053 & 0.007 & 0.004 \\
3-year lag & 0.029 & -0.145 & -0.050 & -0.008 & 0.647 & 0.014 & 0.026 \\
& 0.008 & 0.013 & 0.041 & 0.011 & 0.059 & 0.007 & 0.005 \\
5-year & 0.009 & -0.105 & 0.215 & -0.051 & 0.089 & 0.029 & 0.017 \\
$\quad$ difference & 0.025 & 0.022 & 0.103 & 0.036 & 0.122 & 0.020 & 0.013 \\
5-year log & -0.028 & -0.238 & 0.759 & -0.042 & 0.076 & 0.304 & 0.032 \\
$\quad$ difference & 0.360 & 0.038 & 0.531 & 0.045 & 0.064 & 0.404 & 0.016 \\
With controls & & & & & & & \\
Levels & 0.023 & -0.147 & 0.345 & -0.015 & 0.346 & 0.049 & 0.034 \\
& 0.018 & 0.019 & 0.078 & 0.027 & 0.091 & 0.016 & 0.010 \\
3-year lag & 0.017 & -0.093 & 0.150 & -0.022 & 0.150 & 0.032 & 0.026 \\
& 0.021 & 0.029 & 0.100 & 0.030 & 0.109 & 0.018 & 0.013 \\
5-year & -0.010 & -0.061 & 0.028 & -0.048 & -0.033 & -0.004 & 0.028 \\
$\quad$ difference & 0.037 & 0.030 & 0.146 & 0.055 & 0.176 & 0.030 & 0.020 \\
5-year log & -0.489 & -0.186 & -0.369 & -0.089 & -0.063 & -0.576 & 0.023 \\
$\quad$ difference & 0.584 & 0.042 & 0.968 & 0.080 & 0.103 & 0.716 & 0.027 \\
\hline
\end{tabular}

deflating with wage inflation. Employment microdata is observed back to 1964 and before that date we assume employment by age and gender to be constant at the 1964 level.

Different potential routes to retirement are captured by simulated individuals with eligibilities for social and disability pension, post employment wage, public employee pension, or combinations of these. Combining these routes into a single SSW and PV for each individual involves a straightforward comparison of alternative routes to find the relevant maximum path. Further to the procedure previously described for aggregating over individuals, different exit routes require scaling according to the proportion of those retiring by program. We observe different exit routes back to 1977 and assume the different exit route weighting before 1977 is constant at the 1977 level.

Having constructed the annual retirement incentive index, we can now run a time series OLS regression explaining labor market activity. Estimates of the coefficient on retirement incentive index for various specifications are presented in table 3.2. The upper panel reports coefficients from regressions without additional covariates. The lower panel controls for GNP, GNP growth, and manufacturing employment share. Dependent variables are rates throughout and within each panel the four lines represent different transformations of the data. First, we regress on untransformed levels (of rates) on levels; second, we regress levels on three-year lags, third, we regress 


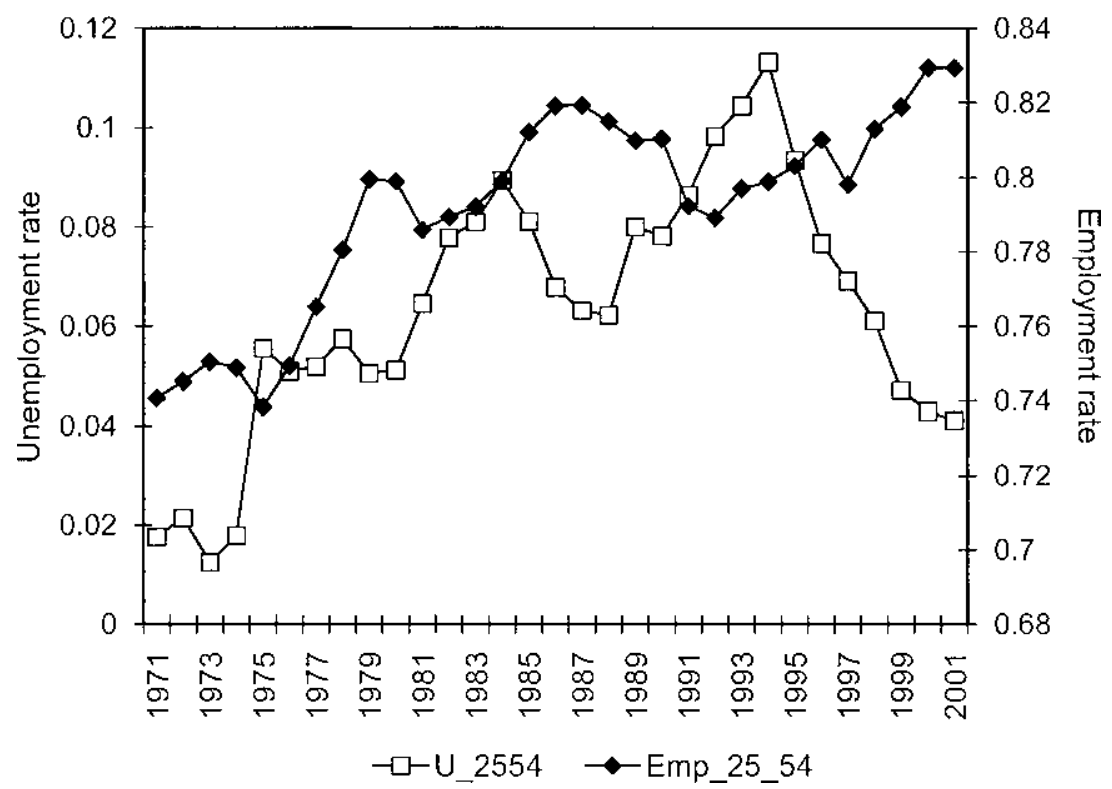

Fig. 3.13 The employment and unemployment rate, prime age group, twenty-five to fifty-four, 1971 to 2001

five-year differences on five year differences; and fourth, we regress log of five-year differences on log of five-year differences.

The first two columns show the impact of incentives on work behavior of the elderly. These show consistently negative (positive) significant effects of retirement incentives on elderly employment (unemployment). Columns (3) through (5) show youth behavior and the last two columns prime age work. To the extent that signs for elderly and younger groups are the same (opposite) we can think of them as being complements (substitutes) for each other in the labor market. With the exception of prime age employment, these younger workers are, if anything, found to be complements for the elderly in that they move together.

Prime age employment and unemployment have the same sign, which is somewhat counterintuitive. This was also the case in the previous section, where elderly employment directly explained prime age activity — prime age unemployment had an anomalous sign. A similar explanation is in order here, too. Consider again figure 3.13, where it can be seen that prime age employment and unemployment trend together for most of the observation period until the cyclical upturn starting in the mid-1990s, largely reflecting secular trends in labor force participation, especially among women, which explains why the share outside the labor force for the prime age group has gone down. 


\subsection{Conclusions}

The purpose of this chapter has been to describe and investigate the relationship between elderly employment and the employment, unemployment, and educational enrollment of young and prime aged workers in the Danish economy. In particular, we studied whether older workers leaving the labor force by way of early retirement programs freed up job opportunities for younger workers. Denmark presented a good test case for this substitution hypothesis because of the sharp drop in labor force participation of the elderly, which occurred following the introduction of the PEW. This key reform and other policy reforms occurring over the period were largely fueled by a concern over rising youth unemployment at the time and provided the variation used to identify effects of elderly labor force participation on other segments of the labor market.

Examining linked microdata spanning a long time period, we find no observable relationship between trends in employment of the older and younger age groups. Similarly, the statistical evidence does not indicate that older workers and younger workers are substitutes. On the contrary, our regression results suggest that if anything, young workers are complements for the elderly in Denmark because youth employment tends to rise and fall together with elderly employment. For prime age workers, on the other hand, both employment and unemployment tend to rise with elderly employment, but this is most likely driven by the secular increase in female labor force participation over the period, bringing more prime aged workers into the labor market.

\section{Reference}

Gruber, J., and D. Wise, eds. 1999. Social Security and retirement around the world. Chicago: University of Chicago Press. 